\title{
OPINIÃO
}

\section{A escolha do padrão de TV digital no Brasil}

Wellington Pereira*

A televisão sempre foi objeto de cobiça e esteve presente, com destaque, nos lares dos brasileiros. Mais de 90\% das residências no Brasil detêm ao menos um aparelho de TV. Ademais, a previsão de crescimento para este mercado em 2006 é de $12 \%$ - algo nada desprezível.

Toda a evolução positiva no consumo de aparelhos e serviços, relacionados à área televisiva, estará marcado por dois fatores que têm ganhado destaque nos últimos anos. Um desses fatores se refere aos novos e modernos formatos de aparelhos de TV. Dois novos materiais têm, crescentemente, delineado as mudanças que vêm ocorrendo e que se intensificarão no futuro próximo acerca do consumo de televisores: o plasma e o cristal líquido. Além de melhor definição da imagem, eles permitem que os aparelhos de TV possam se tornar peças decorativas, podendo ser apreciados tal como quadros pendurados numa parede. O outro fator que vem marcar a transformação desse mercado no Brasil trata da transmissão digital do sinal de TV. Já há algum tempo que os órgãos governamentais fazem e coordenam estudos voltados para uma escolha do padrão de TV digital que será adotado nacionalmente. A TV digital nada mais é que um sistema que transmite dados por meio de um código digital, compatível com a linguagem dos computadores.

O Sistema Brasileiro de TV Digital (SBTVD), cujos princípios foram determinados pelo Decreto Presidencial 4.901, de 26 de fevereiro de 2003, destaca como parâmetro principal no processo de definição do padrão a ser adotado no Brasil, a promoção da inclusão digital. Isto teria como favorecer um maior e crescente acesso da população à Internet através da televisão, junto à possibilidade de expansão do ensino à distância, através desse método.

Nesta perspectiva de revolução tecnológica no mercado de TVs, será possível ao consumidor, sentado na poltrona de sua casa, interagir com a emissora de televisão através de seu controle remoto: ele poderá participar desde uma pesquisa de opinião pública até comprar produtos e verificar seu correio eletrônico.

\footnotetext{
* Mestrando em Economia na Universidade Federal do Paraná (UFPR) e Membro do Grupo de Estudos em Economia Industrial (GEEIN) da Universidade Estadual Paulista (UNESP). Endereço eletrônico: wdspereira@yahoo.com.br
} 
Mas a questão do momento tem sido de qual será o melhor padrão de TV digital para os consumidores brasileiros. De forma geral, defende-se, a partir das prerrogativas apontadas anteriormente, que o padrão seja aquele que não impeça a incorporação de inovações da indústria nacional e abra o maior "leque" de opções de conteúdo para o consumidor.

A escolha do padrão de TV digital no Brasil estava prevista para ocorrer até o dia limite de 10 de março de 2006. No entanto, ela foi postergada sem pré-agendamento. A definição do padrão que vigorará no SBTVD gira em torno de três opções de sistemas: o norteamericano, o europeu e o japonês. Este processo envolve interesses distintos, e as empresas de cada um desses grupos têm realizado exposições acerca de suas qualidades interativas mostrando que estão adequadas às exigências sobre inclusão digital e interatividade. De uma forma geral, os norte-americanos estão atrasados tecnologicamente em relação à mobilidade (transmissões via celulares, por exemplo), mas podendo superar este gargalo rapidamente. Os europeus defendem sua capacidade de ganho de escala, possibilidades de exportação de aparelhos de TV do Mercosul para a Europa com alíquota zero, e oferecem a nomeação de um representante do Brasil no conselho gestor dos projetos de desenvolvimento do padrão europeu. Os japoneses ofereceram financiamentos que podem superar os 400 milhões de euros, a viabilidade da incorporação de inovações tecnológicas brasileiras ao sistema, a quebra de patentes para produção de aparelhos e a vaga para um representante no fórum que decide sobre as inovações no sistema.

A corrida dentre os três sistemas tem sido acirrada, mas o ministro das comunicações, Hélio Costa, aponta que o padrão que possibilite incorporar as inovações desenvolvidas pelos grupos coordenados pelo Centro de Pesquisa e Desenvolvimento em Telecomunicações $(\mathrm{CPqD})$ terá mais chance de ser adotado. Mas dentro do governo ainda há divergências. Enquanto o ministro das comunicações já defendeu, em várias oportunidades, que o escolhido seja o padrão japonês, porque ele atende a todos os pré-requisitos relacionados às necessidades brasileiras (sobretudo, questões da inclusão digital), o ministro do Desenvolvimento, Luis Fernando Furlan, e mais recentemente, a chefe da Casa Civil, Dilma Rousseff, e o ministro da Cultura, Gilberto Gil, estariam propensos ao sistema europeu.

Apesar de grandes semelhanças entre os padrões, uma diferença importante está em torno da transmissão de programas através de telefones celulares. No caso do sistema japonês, favorece-se o uso através das emissoras de TV, enquanto que no europeu há a possibilidade de uso por vários fornecedores de conteúdo. Assim, os lobbies têm sido fortes de todos os lados: empresas de equipamentos, emissoras de televisão e empresas de telefonia. 
Ademais, a decisão acerca da definição do padrão de TV digital a ser adotado se deparou, nas últimas semanas, com um novo elemento que pode postergar por mais tempo a escolha. A prioridade, agora, é a instalação de uma fábrica de semicondutores no Brasil. Isto tornaria possível a realização de pesquisas e desenvolvimento local, e não apenas a montagem de peças e componentes importados. $\mathrm{O} \mathrm{CPqD}$, que coordenou e analisou estudos sobre os três possíveis padrões, alegou a importância de o governo brasileiro utilizar este momento como forma de obter contrapartidas tecnológicas, sendo uma oportunidade única para o desenvolvimento da política industrial nesta área.

Tanto os japoneses, que de certa forma estavam na dianteira, e os europeus pediram mais tempo para avaliar as possibilidades e as condições para o mercado de semicondutores. Apesar de não querer esperar por muito mais tempo, os gestores no âmbito do governo compreendem o fato de ser necessário um tempo para essa avaliação. Mas fontes apuradas pelo jornal Valor Econômico asseguraram que será escolhido o grupo responsável pelo padrão que se comprometa com a montagem da fábrica no país. No entanto, há de se frisar que os investidores têm questionamentos que nem o próprio governo brasileiro ainda sabe responder, tal como ficarão as tarifas de importação, qual será a redução em IPI (Imposto sobre Produtos Industrializados), acesso à mão-de-obra e a formação de pesquisadores.

\section{Anexos}

Matéria publicada na Revista "Isto é", n. 1892, 25 de janeiro de 2006.

Tudo o que você gostaria de saber sobre o futuro da televisão digital, mas não sabia sequer a quem perguntar.

\section{1) Preciso jogar fora minha tevê atual para assistir à tevê digital?}

Qualquer televisor comum, mesmo modelos antigos, vai acessar as imagens digitais transmitidas pelas emissoras de tevê aberta. Todos os modelos com saída para áudio e vídeo (para ligar o DVD e o videocassete) podem ser conectados ao terminal de acesso, que é uma espécie de conversor de sinais digitais.

\section{2) Tenho que trocar de antena?}

A transmissão ocorre na faixa UHF e VHF, portanto as antenas comuns serão capazes de receber o sinal digital.

\section{3) $\mathrm{O}$ que preciso fazer para assistir à tevê digital?}

Primeiro é preciso comprar um terminal de acesso, que deve custar entre $\mathrm{R} \$ 200$ e $\mathrm{R} \$ 600$. Novos serviços surgirão, como o Personal Video Recorder (PVR), que permite interromper a 
novela ou o jogo para assistir depois. Nesse caso, o terminal de acesso pode chegar a $\mathrm{R} \$ 1$ mil e tende a ter recursos cada vez mais parecidos com os de um computador.

\section{4) Tenho de pagar mais para ver tevê no celular?}

Não. O sinal de tevê aberto será transmitido pelas emissoras tradicionais de forma gratuita. $\mathrm{O}$ custo é pago pela audiência do programa e pelos anúncios comerciais.

\section{5) Será preciso ter mais um conversor só para ver tevê a cabo?}

Depende da tecnologia. Alguns terminais de acesso poderão receber sinais dos dois sistemas (tevê aberta e por assinatura).

6) Se eu quiser ver tevê de alta definição (HDTV), tenho que comprar um novo aparelho?

Quem quiser ver alta definição pode aguardar o lançamento dos novos televisores. Hoje, as tevês de plasma e cristal líquido (LCD) vendidas no Brasil têm 720 linhas de resolução, como um DVD. Apesar disso, elas recebem imagens com 480 linhas das tevês aberta e a cabo. Em 2006 serão lançados os televisores de 1.080 linhas, ou alta definição, que vão custar mais de $\mathrm{R} \$ 10$ mil e terão selo apropriado para o consumidor não comprar gato por lebre. Quem tem uma tevê convencional, de tubo, terá no mínimo qualidade de DVD no sistema digital. Sem fantasmas nem sombras e com uma qualidade de som incrível.

\section{7) Acabo de comprar um televisor de plasma. O que faço com ele?}

Basta conectar um terminal de acesso para converter os sinais digitais. Com um aparelho de plasma ou cristal líquido, será possível ter um cinema dentro de casa quando as emissoras transmitirem imagens com qualidade digital.

\section{8) Posso ligar minha tevê digital no home theatre?}

Sim. O sistema digital é compatível com o multicanal de áudio do DVD. Interatividade é a palavra- chave: no sistema digital será possível fazer compras e assistir a até quatro programas em um mesmo canal

\section{9) Posso acessar a internet a partir da tevê digital?}

Para isso é necessário que o terminal de acesso tenha um canal de interatividade, o que significa ter uma linha telefônica, internet de banda larga ou internet sem fio. Nesse caso, cada um com seu respectivo custo de assinatura.

\section{0) Posso ligar a tevê no computador?}

Sim, desde que use o terminal de acesso. 


\section{1) Como será a interatividade?}

Todos os comandos e recursos serão acessados a partir do controle remoto. Teclados, joysticks e mouses também podem ser usados para pilotar a tevê.

\section{2) Vou poder baixar músicas e dados na televisão?}

Sim, no futuro, e depende da emissora transmitir esses dados. Num programa de culinária, ela deixaria a receita disponível para o telespectador, que pode "baixar" o arquivo pressionando um botão no menu da internet. Também se pode enviar e-mails e acessar o banco, mas, no começo, será possível apenas o envio de comandos simples, como respostas para enquetes rápidas.

\section{3) A tevê digital pode transmitir vírus?}

Os cientistas brasileiros alegam ter resolvido o problema ao instalar um sistema de certificação digital no terminal de acesso. Não há histórico de vírus transmitido pela tevê digital na Europa nem no Japão.

\section{4) Posso ligar minha filmadora na tevê digital?}

Sim, desde que a câmera tenha saída USB. Todos os conversores devem vir com esse conector, mas nem todos aceitam dispositivos com saída firewire.

\section{5) Como instalo o terminal de acesso?}

Basta tirar da caixa, ligar o conector à saída "video out" do televisor e o outro cabo na tomada.

\section{6) Posso gravar programas da tevê em DVD?}

Talvez. Tudo depende da autorização da emissora e da política de direito autoral de cada programa.

\section{7) A transmissão digital a cabo é a mesma da tevê digital?}

A tevê a cabo digital já existe e é um serviço fechado e pago. A tevê digital será um sistema aberto e gratuito, basta ter o terminal de acesso para converter o sinal digital.

18) O televisor atual terá a mesma qualidade dos modelos de plasma e cristal líquido?

Não. Transmissão é diferente de resolução, que se mede em linhas exibidas na tela. Cada aparelho tem suas limitações. A tevê digital trará para todos a fidelidade de um DVD, mas a plasma e a cristal líquido estão prontas para exibir imagens de melhor qualidade.

19) Quando houver transmissão em alta definição (HDTV), será preciso equipamento especial?

Até que se defina o padrão de tevê digital no Brasil, na primeira quinzena de fevereiro, todos os televisores precisarão de conversor. Depois eles virão de fábrica com o conversor embutido. 
20) Quanto tempo levará para a programação das tevês abertas e a cabo serem em alta definição?

Depende do investimento financeiro na produção de conteúdo. No Japão, por causa do alto custo, só um terço da programação - cinco horas diárias - é feito em alta definição. O governo brasileiro deseja começar pelas capitais, passando em seguida para as cidades com mais de 500 mil habitantes, e assim por diante. A transmissão da tevê digital começa oficialmente em 7 de setembro. 